\title{
Control assessment for heat integrated systems. An industrial case study for ethanol recovery
}

Mauricio Iglesias, Miguel; Huusom, Jakob Kjøbsted; Sin, Gürkan

Published in:

Chemical Engineering and Processing

Link to article, DOI:

10.1016/j.cep.2012.11.003

Publication date:

2013

Document Version

Early version, also known as pre-print

Link back to DTU Orbit

Citation (APA):

Mauricio Iglesias, M., Huusom, J. K., \& Sin, G. (2013). Control assessment for heat integrated systems. An industrial case study for ethanol recovery. Chemical Engineering and Processing, 67, 60- 70.

https://doi.org/10.1016/j.cep.2012.11.003

\section{General rights}

Copyright and moral rights for the publications made accessible in the public portal are retained by the authors and/or other copyright owners and it is a condition of accessing publications that users recognise and abide by the legal requirements associated with these rights.

- Users may download and print one copy of any publication from the public portal for the purpose of private study or research.

- You may not further distribute the material or use it for any profit-making activity or commercial gain

- You may freely distribute the URL identifying the publication in the public portal 


\section{Accepted Manuscript}

Title: Control assessment for heat integrated systems. An industrial case study for ethanol recovery

Authors: Miguel Mauricio-Iglesias, Jakob K. Huusom, Gürkan Sin

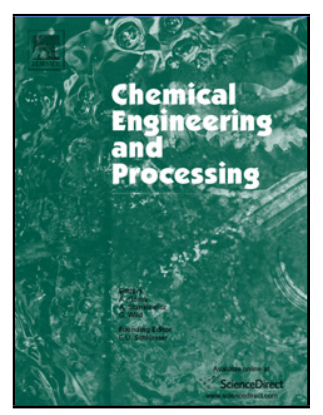

PII:

S0255-2701(12)00215-2

DOI: doi:10.1016/j.cep.2012.11.003

Reference: CEP 6200

To appear in: Chemical Engineering and Processing

Received date: 30-3-2012

Revised date: 8-11-2012

Please cite this article as: M. Mauricio-Iglesias, J.K. Huusom, G. Sin, Control assessment for heat integrated systems. An industrial case study for ethanol recovery, Chemical Engineering and Processing (2010), doi:10.1016/j.cep.2012.11.003

This is a PDF file of an unedited manuscript that has been accepted for publication. As a service to our customers we are providing this early version of the manuscript. The manuscript will undergo copyediting, typesetting, and review of the resulting proof before it is published in its final form. Please note that during the production process errors may be discovered which could affect the content, and all legal disclaimers that apply to the journal pertain. 


\title{
Control assessment for heat integrated systems. An industrial case study for ethanol recovery
}

Miguel Mauricio-Iglesias, Jakob K. Huusom, Gürkan Sin ${ }^{*}$

CAPEC - Department of Chemical and Biochemical Engineering, Technical University of Denmark, 2800 Lyngby, Denmark;

To be submitted to: Chemical Engineering and Processing: Process Intensification

Number of pages: 14

Number of figures: 10

Number of tables: 8

*Corresponding author: Gürkan Sin

Department of Chemical \& Biochemical Engineering, Soltofts Plads, Building 229

Technical University of Denmark (DTU) DK-2800 Kgs. Lyngby, Denmark

Phone:+45 45252806 \& Fax :+45 45932906

\section{Highlights}

-Heat integration is needed for energy reduction but can deteriorate controllability

-Soundly designed controllers can handle complex processes

-The deterioration of controllability was handled by the controllers

-Large energy savings are possible with a good dynamic response

\begin{abstract}
:
Heat integration is essential for reducing the energy consumption of process industries. However, it may render the dynamic operation more interactive and difficult to control. This paper assesses the implications of heat integration in controllability and performance in energy reduction. The assessment, both on open loop and closed loop, was carried out based on an industrial case study and compared to a modified case without heat integration. Although the heat integrated system
\end{abstract}


displayed a certain deterioration of controllability, the control system made possible an efficient operation. To this goal, different control systems were tested, from a decentralized control system to a model predictive controller. The type of controller used in the process barely influenced the performance of the process since the aim was exclusively to ensure the regulation of the process to fixed setpoints. The reduction of energy consumption achieved thanks to heat integration was considerably larger than the losses due to poor control of the process, confirming the importance of heat integration in energy intensive processes.

Keywords: Heat integration; distillation; controllability; decentralized control; model predictive control.

\section{Introduction:}

Integration of mass and heat has been for decades one of the main strategies in process industry to reduce the consumption of energy, raw matters and utilities. However, it remains a challenge for process operation, despite being so commonly applied (and taught) in the design of industrial processes. Processes tend to become more complex and interrelated with more recycles, heat integration streams and fewer surge tanks in order to reduce both capital costs and energy. This leads to highly interactive processes with complex dynamics. Integration of processes frequently leads to controllability issues caused by one or several of the following reasons [1]: i) reduction of the number of degrees of freedom (DOF), rendering a decrease of actuation possibilities; ii) disturbances are not dampened in a single unit and propagate to the whole process through the integrated units; iii) higher order interactions between process variables contribute to non-linear behaviour; iv) the operating windows often become narrower, which limit the range of actuation for the controllers. A process will generally become more difficult to control if the degree of integration is higher, which has been reported as one of the reasons explaining the difference between the potential of highly integrated processes (e.g. intensified processes) and its state of implementation in industry. For instance, [2] analysed the controllability of distillation systems with external heat integration for a four component stream and came to the conclusion that depending on the streams used for integration, the system could be very hard to control due to poor controllability. Gross et al. [3] assessed three control structures in an industrial case of heat integrated distillation columns both in terms of dynamic simulation and common controllability indexes (Morari resilience index, relative gain array, condition number). Based on their results, they came to the conclusion that such 
indexes, albeit useful, have to be complemented with dynamic simulation of a high fidelity model, in particular including hydraulics and level variation.

The aim of process integration itself can be compromised due to poor controllability (meaning here the ease to achieve acceptable control performance [4]). If the plant is difficult to control, it will seldom work at its nominal operating point, offsetting the theoretical increase of efficiency gained through process integration. A sound control strategy is needed to tackle the process as a whole which involves, in most cases, the use of multivariable control. Model Predictive Control (MPC) is currently the state of the art for multivariable control in industry [5-7] as it provides a suitable framework for control of interacting systems with constraints. Although MPC is supported in a sound theoretical background [8-11], the application of MPC still represents some challenges related to the controller structure and implementation such as: which variables should be controlled by MPC or by the regulatory layer? The variables controlled by MPC, can they be updated in a frequent enough basis? How should the MPC controller be tuned and, should this be related to the regulatory control layer? [12].

This paper shows an assessment of the controllability implications of heat integration using as a case study an actual industrial process consisting of two distillation columns in series. To achieve this aim, the process is compared to the equivalent without heat integration, in order to compare the potential deterioration of controllability induced by energy integration and the benefits of energy savings. Besides, different control systems (decentralized, MPC) are benchmarked to assess the applied solutions to the control of the process. This paper is organized as follows. The case study and the dynamic model characteristics are briefly outlined. Then, the different control systems and simulation tests performed are described. Finally the results of the tests are presented and critically discussed, before concluding about the effect of heat integration on process controllability.

\section{Methods}

\subsection{Definition of case study}

An industrial case study was used as an example to approach the controllability problems related to heat integration. The plant has been described into detail elsewhere [13] and it is just briefly described for the sake of completeness. The process consists of two distillation columns in series with heat integration (Fig. 1). The feed is composed of varying concentrations (nominal composition in brackets) of ethanol $(30 \% \mathrm{w} / \mathrm{w})$, water $(65 \% \mathrm{w} / \mathrm{w})$ and smaller fractions of heavier (ca. $5 \% \mathrm{w} / \mathrm{w}$ ) and lighter (ca. $0.1 \% \mathrm{w} / \mathrm{w}$ ) compounds at $323 \mathrm{~K}$. The product of the process is the 
bottom stream of the second column; the bottom stream of the first column and the distillate of the second column are waste streams. The distillate of the second column is a purge of the light compounds in the feed, and therefore has a very low flowrate.

The feed concentration does not change continuously but batchwise (approx. every $8 \mathrm{~h}$ ), since the feed is provided from different tanks upstream. The nominal point of operation corresponds to an ethanol concentration of $30 \% \mathrm{w} / \mathrm{w}$ and the designed setpoints correspond to the steady state design of the system at the nominal point. The heat integration is done both forward and backward. In the first case, part of the vapour flow of the first column is condensed in one side of the reboiler of the second column and its latent heat is used to create the vapour build-up in the second column. The other part of the heat integration is carried out backward since both bottom streams from the two columns are used to preheat the feed.

A modification of the studied process was done in order to compare the effect of heat integration. Therefore, in the modified flowsheet (Fig. 2), a feed preheater was added in order to substitute the heat exchangers for the bottom flows of the two columns and the reboiler in the second column is fed with an external source of steam. Energy to the preheater is supplied by an external stream which is assumed to control perfectly the outlet temperature of the feed. The heat duty of the second column is regulated by a control loop. The two additional energy supplies (preheater and second reboiler) represent an increase of $36 \%$ and $25 \%$ in energy consumption respectively, with respect to the total of the heat-integrated case study. For the sake of comparison between process dynamics, the case without heat integration has been kept as close as possible to the original process.

\subsection{Dynamic model}

The dynamic model of the plant was implemented in Matlab/Simulink. The two packed distillation columns were modelled as equilibrium stages as it has been reported that this approach is also suitable for packed columns [14]. The equilibrium stages were considered at bubble point conditions [15] considering the following assumptions: i) vapour hold-up is neglected compared to liquid hold-up; ii) pressure does not vary with time; iii) liquid enthalpy variations are neglected compared to vaporization heat; iv) molar vaporization heat is close for the key components and, hence, constant molar flow assumption holds [14]. Given these assumptions, the following equations are used to simulate the column:

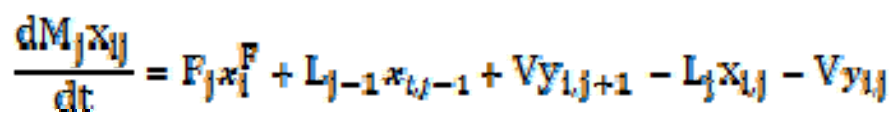


where $M$ stands for the molar hold-up of the stage, $x$ and $y$ stand for liquid and vapour molar fractions respectively, $L$ stands the liquid flow, $V$ stands the vapour flow and $F$ stands for the feed flow. The subscripts $i$ and $j$ represent the compound and the equilibrium stage respectively.

The relationship between liquid flow dynamics and liquid hold-up for the packed columns were modelled according to equation (2) [16]

$\mathrm{M}_{\mathrm{L}}=\left(12 \frac{\eta_{\mathrm{L}} \mathrm{u}_{\mathrm{L}} \mathrm{a}^{2}}{\rho_{\mathrm{L}} \mathrm{g}}\right)^{1 / 3}\left(\frac{\mathrm{a}_{\mathrm{h}}}{\mathrm{a}}\right)^{2 / 3}$

where $M_{L}$ is the liquid molar hold-up (mol), $a$ and $a_{h}$ are the specific area of the packed column (dry and wet respectively; $\left.\mathrm{m}^{2} / \mathrm{m}^{3}\right), \rho_{L}$ is the molar density of the liquid ( $\left.\mathrm{mol} \mathrm{m} \mathrm{m}^{-3}\right), \eta_{L}$ is the viscosity of the liquid $\left(\mathrm{kg} \mathrm{m}^{-1} \mathrm{~s}^{-1}\right), g$ is the acceleration of gravity $\left(\mathrm{m} \mathrm{s}^{-2}\right)$ and $u_{L}$ is the superficial velocity of the liquid $\left(\mathrm{m} \mathrm{s}^{-1}\right)$.

For the feed stage(s), assumption iii) does not hold unless the feed is saturated liquid of vapour. Therefore, an energy balance has to be solved for this stage, which can be formulated as an isenthalpic flash (or PH-flash):

$$
\mathrm{L}_{\mathrm{j}} h_{\mathrm{j}}+\mathrm{V}_{\mathrm{j}} \mathrm{H}_{\mathrm{j}}=\mathrm{F}_{j} \mathrm{~h}_{\mathrm{F}}+\mathrm{L}_{\mathrm{j}-1} \mathrm{~h}_{\mathrm{j}-1}+\mathrm{V}_{\mathrm{j}+1} \mathrm{H}_{\mathrm{j}+1}
$$

where $h_{j}$ and $H_{j}$ are respectively the enthalpies of the liquid and vapour leaving the feed stage. Vapour-liquid equilibrium was described with the modified Raoult's law, using Wilson's equation to determine the activity coefficients, as it is the simplest model that accurately predicts the ethanolwater azeotrope [17]. The lighter and heavy compounds mentioned previously cannot be disclosed for confidentiality reasons. However, some indications can be given about their relative volatility in relation with the key (ethanol and water) that includes them. The lowest relative volatility of the light compounds with respect to ethanol was estimated as $\alpha>1.48$ although a value of $\alpha>1.90$ was achieved in the sections where the concentration of the light compounds were significant $(x>0.01)$. The heavy compounds were much less volatile than water $(\alpha>10$ in all the process). Therefore, and given that they are the most abundant compounds in the whole process, ethanol and water were selected as the light and heavy key.

\subsection{Control design}

Base case. A decentralized control structure is implemented in order to ensure the following objectives: 
i) The product (second column bottoms) must contain at least $86 \% \mathrm{w} / \mathrm{w}$ of ethanol with traces of the lighter compounds $(>0.005 \%)$

ii) The waste (first column bottoms) must contain less than $0.1 \% \mathrm{w} / \mathrm{w}$ of ethanol

iii) The pressure in the reflux drum of the first column must be tightly controlled in order to avoid cavitation in the pump located in its outlet and to ensure that the condensate in the second column reboiler flows into the reflux drum

iv) Since the vapor flow in the second column is not constant but depends on the heat "integrated" in the reboiler, care must be taken so that flooding is avoided in the second column.

Apart from the loops devoted to keep level and pressure controlled in the columns, with no steady state effect on the operation, four control loops can be manipulated to ensure a smooth operation and the previous objectives (Table 1). The main idea of this control structure is to work at full energy capacity (the throughput manipulator is indeed the heat duty to the first column) and use the feed flow rate as a manipulated variable. Loops 1 and 3 ensure the quality requirements of the product and waste. Loop 2 is used to tightly control the pressure in the reflux drum and loop 4 keeps the loading of the second column out of the flooding conditions by manipulating the vapour flow in the column. As for the rest of the loops, they stabilize the system and cannot be used to modify the operation because either they lack steady state action on the process (i.e. loops on integrating variables as 5-8 and loop 10), either their effect is merely local, such as loop 9 that guarantees the condensation of all the vapour in the second column. In this work, we will keep the same actuators and sensors in all our analysis.

Model Predictive Control. A linear representation of the dynamic system model is achieved by conducting a series of step response simulation in all manipulated and disturbance variables based on the same initial steady state condition. Based on these transient responses the linear system representation can be expressed as a transfer function matrix, $\mathrm{G}(\mathrm{s})$, containing all dynamic couplings between process outputs and external inputs. All transfer functions were fitted as first or second order systems with time delays (Table 2).

The transfer function model of the plant is transformed to a discrete time state space description as follows:

$\mathrm{x}_{\mathrm{k}+1}=\mathrm{A} \mathrm{x}_{\mathrm{k}}+\mathrm{B}_{u} \mathrm{u}_{\mathrm{k}}+\mathrm{B}_{\mathrm{d}} d_{\mathrm{k}}+\mathrm{w}_{\mathrm{k}}$

$\mathrm{y}_{\mathrm{k}}=\mathrm{Cx}_{\mathrm{k}}+\mathrm{y}_{\mathrm{k}}$ 
where $x$ are model states, $u$ are inputs, $d$ are disturbances, $y$ are outputs and $w$ and $v$ are the process and measurement noise respectively. In order to ensure offset free control in case of model mismatch or unmeasured sustained disturbances, the model is augmented with as many disturbance states as outputs $[18,19]$. Based on the augmented system description an ordinary Kalman filter can be designed and an MPC controller synthesised based on the following performance cost function $\min _{\mathrm{u}} \sum_{\mathrm{j}=1}^{\mathrm{h}}\left\|\mathrm{y}_{\mathrm{sp}, \mathrm{A}}-\mathrm{y}_{1}\right\|_{\mathrm{Q}}+\left\|\Delta \mathrm{u}_{\mathrm{j}}\right\|_{\mathrm{R}}$

Where $h$ represents the prediction and control horizon, $y_{s p}$ are reference signals for the controlled outputs, $y$, and the matrices $Q$ and $R$ give relative weights to the contributions from the individual tracking errors and on the speed of the individual actuators respectively. Box constraints can be formulated both on the position and the speed of the actuators.

\subsection{Control system scenarios}

Four different scenarios were considered in order to assess separately the controllability problems related to the design of the process and to the structure of the controller (Table 3). Scenario 1 is considered to assess the deterioration on controllability of the plant if the interactions are reduced by removing the heat integration streams. Hence, energy to the feed preheaters and the second column reboiler is supplied by external heat exchangers (Fig. 2). The control structure in scenario 1 corresponds with figure 2 except for loop 4, which manipulates the heat duty to the $2^{\text {nd }}$ reboiler from an external source.

Scenarios 2-4 keep the same actuators and sensors displayed in Fig. 1. Scenario 2 is the base case study, where the four loops are controlled by PID controllers, independently tuned. A MPC controller is implemented in scenarios 3 and 4 but in a different way. In scenario 3, the MPC controller only acts upon loops 1 and 3. Loops 2 and 4 are independently controlled by PID controllers. In scenario 4, the four loops are controlled by the MPC controller. The reason for using the MPC just for loops 1 and 3 in scenario 3 was motivated by the difference between the four loops. Hence, loops 1 and 3, which control the top and bottoms concentration, have setpoints that are likely to be changed (by an operator or by a controller/optimiser higher in hierarchy). Their dynamics can be efficiently controlled with the MPC sampling time then. On the contrary, loops 2 and 4 are related to the hydraulic flows in the columns (and therefore to the smooth running of the process). Their setpoints are unlikely to be changed during the plant operation, as far as the working 
pressure in the columns is not varied. It may be needed to execute these loops at a higher frequency than loops 1 and 3.

Controller tuning. Tuning of an MPC controller is, in practice, a complex task given the large number of parameters (error weight, penalty on moves, prediction horizon) that must be appropriately set [12]. Furthermore the integrators added to the model in the MPC give a deliberate plant/model mismatch which renders the analysis more complex [20].

To tune the MPC controller, the method described by Wojsznis et al. [21] was followed, but the tuning turned out to be too tight giving place to a "ringing" behaviour, even for small disturbances. The tuning was corrected by increasing the penalty on moves individually for each loop until the controller did not ring for a $10 \%$ disturbance in feed composition. The tuning of the MPC determined the aggressiveness of the tuning of the rest of control systems. A comparison between different control structures is often hampered by the differences in tuning, which largely determine the efficacy of a controller. In order to allow a fair comparison between the four scenarios, the controllers were tuned so that the maximum peaks of the sensitivity function, $\|\mathbb{S}\|_{m}$, were the same for all loops in the different scenarios. Therefore, all the controllers can be considered as equally robust, i.e. the same degree of confidence on the model is used to tune them. Arguably, a 4x4 MPC controller does not have just 4 loops but 16 coordinated loops. However, only the $\|\mathbb{S}\|_{w}$ of the pairings in scenario 2 were considered. The values of $\|\mathbb{S}\|_{m}$ for the four loops were respectively $1.01,1.21,1.79$ and 1.07. Only loop 3 is above the recommended 1.0-1.2 value, although this is rather a case related recommendation than a universal rule [11]. As a final remark, scenario 1 was also tuned with the same $\|S\|_{\text {. }}$ even though strictly, this does not imply a comparable degree robustness since the plant dynamics in scenario 1 is different.

\subsection{Control performance assessment: tests and metrics}

Two different simulation tests have been designed to assess the closed-loop performance of the corresponding control systems. The first case deals with the ability to reject a step disturbance $(+10 \%)$ in the feed composition. The second case is a long simulation with a $32 \mathrm{~h}$ period, which corresponds to the normal plant operation with the main types of disturbances encountered, namely: i) step changes in feed composition every $8 \mathrm{~h}$ (corresponding to batch changes); ii) high frequency disturbances modelled as white noise (standard deviation of $\sigma=70 \mathrm{MJ} / \mathrm{h}$, equivalent to $1 \%$ of the nominal value; sampling time $1 \mathrm{~min}$ ) in the heat duty supply to the $1^{\text {st }}$ column; and iii) daily 
variation (frequency $1 \mathrm{day}^{-1}$ or $6.94 \cdot 10^{-4} \mathrm{~min}^{-1}$ ) of cooling water temperature $( \pm 2 \mathrm{~K})$, corresponding low frequency disturbances.

The performance metrics used to characterize the performance of the controllers are the integral of the absolute error (IAE) and the total variation (TV) of inputs, defined as

$$
\begin{aligned}
& \mathrm{IAE}=\int_{0}^{*}\left|y-y_{s p}\right| d t \\
& \mathrm{TV}=\sum_{t=1}^{\infty}\left|u_{y+1}-u_{j}\right|
\end{aligned}
$$

The production ( $\mathrm{kmol}$ of ethanol/h at the bottom of the second column), the specific energy consumption (MJ per kmol of ethanol produced) and the recovery percentage (ratio of the production and the ethanol treated by the process) were selected as metrics related to the operation of the process.

\section{Results and discussion}

\subsection{Open-loop sensitivity analysis}

An analysis of the impact of a disturbance in feed composition on the plant was performed at steady-state (open loop) by calculating the sensitivity of controlled variables to disturbances at the controlled variable setpoint value, defined as:

$$
s a=\left.\frac{\partial C V}{\partial D V}\right|_{y=y_{s p}}\left(\frac{S_{D V}}{S_{C V}}\right)
$$

Where $C V$ is a controlled variable, $D V$ is a disturbance, and $S_{D V}$ and $S_{C V}$ are the scaling factors for the disturbance and the controlled variable respectively.

The sensitivity measure, sa, indicates the impact of a disturbance on the controlled variable and its deviation from the setpoint. Hence it constitutes a useful indicator of the controllability of the system at setpoint (the lower the sensitivity, the easier to control the system at setpoint, [22, 23]) The results show that the controlled variables $(\mathrm{CV})$ in loops 1 and 2 are more sensitive to the considered disturbance in the scenario without heat integration whereas the CVs in loops 3 and 4 are more sensitive in the heat integration (table 4).

These results suggest that the controllability becomes relatively difficult with heat integration on CV3 and CV4 as the response of the controlled variables to disturbance becomes markedly pronounced ( 3 fold for CV3 and 30 fold for CV4 see table 4 as compared to no heat integration). This results confirmed earlier analysis in heat integration systems. 
On the other hand, the results for CV1 and CV2 sensitivity indicate that the controllability becomes easier in case of heat integration. This is due to multivariable and nonlinear interaction in the system that can be explained as follows. The sensitivity of CV1 (temperature in the stripping section) is higher in the case without heat integration because the preheater of the feed tend to dampen the effect of the disturbance. In effect, if the feed composition in ethanol (light key) increases, the temperature of the stripping section will decrease due to increase of ethanol everywhere in the column. As a consequence, the temperature of the bottoms stream will be lower and the feed temperature will decrease too, since less heat will be exchanged in the preheater. Finally, a decrease in feed temperature will decrease the amount of feed vaporized, dampening the effect of the disturbance. Since in the case without heat integration, it is considered that the preheater controls perfectly the temperature of the feed entering the column, the effect of the disturbance does not decrease.

The sensitivity of CV2 (pressure in the reflux drum) has a different sign in the two cases. Actually, two factors related with the disturbance contribute to the change in CV2: i) an increase in the vapour flow in the column, originated by an increase in feed composition, leads to an increase in pressure in the drum and ii) a decrease in temperature of the condenser, caused by a higher concentration of ethanol in the top of the column, leads to a decrease of pressure in the drum. The second factor has a higher weight in the heat integrated case (3-fold higher sensitivity of CV3).

\subsection{Closed loop disturbance step-response analysis}

Control performance metrics. The first test (step change of $+10 \%$ in the feed composition of ethanol) allowed to check the ability to reject a disturbance and attain a new steady state. The metrics related to the control performance show that the efficacy of each system depends on the loop considered, despite the criterion used to tune the controllers. It is noteworthy that the scenarios 2 and 3 present essentially similar results except for the error on loop 3. Scenario 4 shows a very good and fast rejection of the disturbance in loop 1 which is achieved on expenses of the rests of the loops. In effect, it can be seen (Fig 3-6) that the disturbance is quickly rejected in scenario 4 by the MPC controller but it affects then the rest of the loops (0.1-0.2 h after the disturbance). This is one of the consequences of the coordinated action of the MPC controller. On one hand, the disturbance in loop 1 is rejected but the action of the four actuators will transport the variability to the other loops. Indeed, this is taken into account by minimising the cost function at each time step. Any 
variation in tuning (and variable scaling) can have a large effect on the priority of the errors to be supressed. This is partially avoided in scenario 3. Although a coordinated action of all the available actuators may be more efficient, the separation of a MPC controller for loops 1 and 3, and a decentralized PI for loops 2 and 4 gives place to interesting possibilities. The reason for splitting the MPC is here more apparent with the results obtained. Loop 2, for instance, controls the pressure in the reflux drum, which has an influence on the reflux flow and distilled flow. Therefore, the goal for loops 2 and 4 is not actually tracking a certain setpoint but ensure that variations in the controlled variables $(\mathrm{P}$ and $\Delta \mathrm{P})$ are minimised so that the flows in the system do not vary continuously.

Process performance metrics. As for the metrics during the step disturbance related to the performance of the operation, Table 6 shows the value of the indicators and their difference compared to the value indicator at steady state. In all the cases, the averaged concentration of the product was of $86.1 \% \mathrm{w} / \mathrm{w}$, therefore keeping the specification.

Checking the effect of heat integration, the energy consumption is indeed much higher $(+46 \%)$ in scenario 1 . It can be seen that, although energy consumed during the test ( $1 \mathrm{~h}$ dynamic simulation) is higher than the steady state value, the difference is very low compared to the savings between scenarios 2-4 and scenario 1. As a consequence, any potential deterioration of controllability does not jeopardise the savings in energy and heat integration is largely profitable.

Concerning scenarios 2-4, it can be seen that scenario 4 slightly outperforms the rest of system in terms of production, recovery and energy consumption which are closer to the steady state values. The performance metrics in scenario 4 is enhanced by the quick disturbance rejection. Hence, the amount of ethanol lost in the first column bottoms decreases and more ethanol is recovered, lowering the specific energy consumption. However, it is noteworthy that the three control systems give close results, suggesting that for a given control structure (actuators and sensors), the performance of the controllers can be improved only to a certain point. Indeed, the improvement of controller performance that can be achieved by tuning alone is lower than if changes in the location of actuators and sensors are also considered [13].

\subsection{Plant operation test}

The simulation period in this test is $32 \mathrm{~h}$, which corresponds to 4 cycle operation of the distillation column. The goal of this simulation is to test the behaviour of the plant and the control systems with several simultaneous and different disturbances, as it would happen during real plant operation. 
Control metrics. The metrics related to control performance show again that, even if the loops have been tuned at the same\|S\|s, that the results depend on the particular loop. Scenario 1 performs consistently well in all the loops, in particular displaying a large difference in loop 4. It must be recalled that this loop is not comparable to the rest of the scenarios since the actuator is essentially different. For the heat integrated scenarios, scenario 3 represents a good trade-off between the IAE and the TV metrics and has the best indicators in 6 out of 8 cases. In particular, comparing scenarios 3 and 4 (Table 7 and Fig.4) it can be seen that splitting the regulation into two groups allowed a better rejection of noise disturbances in the system, while keeping a very good action against the step disturbances in the feed composition. As stated earlier, the goal for loops 2 and 4 is rather keeping variability in pressure and pressure drop at a minimum in order to avoid upsetting the running of the process. Both loops are very sensitive to variations in vapour build-up in the column which made the controller in scenario 4 to coordinate all the actuators in order to supress the variations in those loops, therefore "transporting" some of the variations to the rest of the loops. It can be argued that this could be prevented by "detuning" or decreasing the penalty on errors associated to loops 2 and 4. However, this would have been detrimental to the rejection of the low frequency disturbances (daily variations of cooling water temperature) and a large offset would have appeared for loops 2 and 4.

Comparing the two processes, scenario 1 barely presents better metrics than scenario 3 , showing that good control command can be achieved in the heat integrated case with an appropriated control system.

Process performance metrics. As for the performance of the operation (Table 8), it can be seen that the difference become attenuated when the evaluation is averaged for a long period, even if other disturbances are added. Of course, this would depend also on the actual disturbances that the process would endure; the more severe, the more important the controllability of the process would become.

Comparing scenario 1 with scenarios 2-4, the energy savings, exclusively due to design of the process, were considerable and largely exceed any potential deterioration due to poor controllability. Therefore heat integration can be applied to the process enabling a reduction of the energy consumption that can be maintained during the dynamic operation of the plant.

As for scenarios 2-4, they all behaved comparably with scenario 3 slightly outperforming the others. In all the cases, the averaged concentration of the product was of $86.1 \% \mathrm{w} / \mathrm{w}$, therefore keeping the specification for further recovery of the ethanol stream. As suggested earlier, the performance 
regarding operation metrics remains similar for a given control structure regardless of the tuning of control system.

It is worth mentioning that further energy savings can be achieved by allowing the MPC to modify the setpoints of the plant and formulating the objective function as an optimization of the energy consumption and/or an economic objective.

\section{Conclusions}

In this study, we have investigated the impact of heat-integration in distillation columns on their controllability and process performance based on an industrial case study. Open loop sensitivity analysis of the disturbance confirmed the controllability becomes significantly more difficult in heat-integration compared to the no-heat integration case. This puts more emphasize on proper tuning of the controller to reject disturbances. Closed-loop simulations showed that the response of the no-heat integrated case was in effect less interactive and sensitive to disturbances. Closed loop disturbance analysis on the heat-integration system considering both decentralized (PID) and multivariable (MPC) controllers revealed the following for control performance and process performance metrics: the process could be successfully operated for both decentralized and multivariable controllers although the proper tuning of the MPC remains a challenge. The simulation clearly showed that the controller needed much more actuation when the process couplings are increased by heat integration.

To sum up, the conclusions of this work are the following:

- i) The reduction of energy consumption achieved thanks to heat integration is considerably larger than the losses due to poor control of the process, confirming the importance of heat integration in energy intensive processes.

- ii) The controllability of the process was indeed deteriorated when heat integration was implemented. Nevertheless, this was effectively handled by both a decentralized control system and a MPC controller on a dynamic simulation representative of the process.

- iii) For the conditions and tuning methodology used in this study, the MPC and the decentralized control structure were similar in terms of process performance. Their role was to carry out exclusively the regulation of the process.

\section{References}


[1] N.M. Nikačević, A.E.M. Huesman, P.M.J. Van den Hof, A.I. Stankiewicz, Opportunities and challenges for process control in process intensification, Chem. Eng. Proc.

[2] G.R. Salehi, M. Amidpour, K. Hassanzadeh, M.R. Omidkhah, Controllability analysis of heat integrated distillation systems for a multicomponent stream, Comput. Chem. Eng. 36 (2012) 282-293.

[3] F. Gross, E. Baumann, A. Geser, D.W.T. Rippin, L. Lang, Modelling, simulation and controllability analysis of an industrial heat-integrated distillation process, Comput. Chem. Eng. 22 (1998) 223-237.

[4] S. Skogestad, I. Postlethwaite, Multivariable Feedback Control: Analysis and Design , 2nd ed., Wiley-Interscience $<$ SKU> 9780470011683ING, 2005.

[5] M. Kano, M. Ogawa, The state of the art in chemical process control in Japan: Good practice and questionnaire survey, J. Process Control 20 (2010) 969-982.

[6] S.J. Qin, T.A. Badgwell, A survey of industrial model predictive control technology, Control Eng. Pract. 11 (2003) 733-764.

[7] T.L. Blevins, G.K. McMillan, W.K. Wojszni, M. Brown, Advanced Control Unleashed: Plant Performance Management for Optimum Benefit | ISA, ISA - The Instrumentation, Systems and Automation Society, 2003.

[8] J.A. Rossiter, Model-Based Predictive Control - A Practical approach, CRC Press, 2004.

[9] E.F. Camacho, C. Bordons, Model Predictive Control, Advanced Textbooks in Control and Signal Processing. Springer, 2007.

[10] J.B. Rawlings, D.Q. Mayne, Model Predictive Control - Theory and Design , Nob Hill Publishing., 2009.

[11] J.M. Maciejowki, Predictive control with constraints, Pearson Education, 2002.

[12] M.L. Darby, M. Harmse, M. Nikolaou, MPC: current practice and challenges., ADCHEM 2009 (2009).

[13] M. Mauricio-Iglesias, K. Johanssen, S.B. Jorgensen, G. Sin, A framework for systematic review, analysis and improvement of operation and control systems in process industries, Ind. Eng. Chem. Res. (Submitted).

[14] S. Skogestad, Dynamics and control of distillation columns - A critical survey, IFAC Symposia Series DYCORD+ 1992 (1992).

[15] J.D. Seader, E.J. Henley, Separation Process Principles, 2nd ed., Wiley, 2005.

[16] R. Billet, M. Schultes, Physical model for the prediction of liquid hold-up in two-phase countercurrent columns, Chem. Eng. Technol. 16 (1993) 370-375.

[17] J.M. Smith, H.C. Van Ness, M.M. Abbot, Introduction to Chemical Engineering Thermodynamics, 6th ed., McGraw Hill, 2001.

[18] K.R. Muske, T.A. Badgwell, Disturbance modeling for offset-free linear model predictive control, J. Process Control 12 (2002) 617-632.

[19] G. Pannocchia, J.B. Rawlings, Disturbance models for offset-free model-predictive control, AIChE J. 49 (2003) 426-437. 
[20] J. Huusom K., N.K. Poulsen, S.B. Jørgensen, J.B. Jørgensen, SISO offset-free model predictive control based on ARX models, J. Process Control (In Press).

[21] W. Wojsznis, J. Gudaz, T. Blevins, A. Mehta, Practical approach to tuning MPC, ISA Trans. 42 (2003) 149-162.

[22] S. Skogestad, Near-optimal operation by self-optimizing control: From process control to marathon running and business systems, Comput. Chem. Eng. 29 (2004) 127-137.

[23] M.K.A. Hamid, G. Sin, R. Gani, Integration of process design and controller design for chemical processes using model-based methodology, Comput. Chem. Eng. 34 (2010) 683-699. 
Table 2. Plant transfer function for scenarios 2-4 (from [11]). Time in minutes

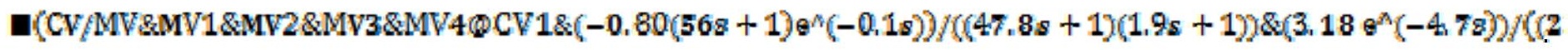


Table 1. Loops for control of operation and variables paired. The numbering of the loops corresponds to that of Fig. 2

\begin{tabular}{lll}
\hline Loop & Controlled variables & Manipulated variables \\
\hline CL1 & Concentration in bottom 1st column & Feed flow \\
CL2 & Pressure in reflux drum & Cooling water flow \\
CL3 & Concentration in reflux drum & Reflux flow \\
CL4 & Pressure drop in 2nd column & Vapor flow to 2nd reboiler \\
\hline
\end{tabular}


Table 2. Plant transfer function for scenarios 2-4 (from [11]). Time in minutes 251658240

\begin{tabular}{|c|c|c|c|c|}
\hline IMV & MV1 & MV2 & MV3 & MV4 \\
\hline \multirow{2}{*}{ CV1 } & $-0.80(56 s+1) e^{-0.1 s}$ & $3.18 e^{-4.7 s}$ & $-1.46 e^{-0.5 s}$ & $0.93 e^{-5.1 s}$ \\
\hline & $(47.8 s+1)(1.9 s+1)$ & $(23.6 s+1)$ & $(17 s+1)$ & $(21.3 s+1)$ \\
\hline \multirow{2}{*}{ CV2 } & $-2.26 e^{-0.15 s}$ & $-4.99(26 s+1) e^{-0 .+s}$ & $-0.32 e^{-0.05}$ & $-1.54(34 s+1) e^{-0.9 s}$ \\
\hline & $(7.5 s+1)$ & $\overline{(23 s+1)(8.2 s+1)}$ & $(48 s+1)$ & $\overline{(30 s+1)(6.5 s+1)}$ \\
\hline \multirow{2}{*}{ CV3 } & $-3.05 e^{-9.9 s}$ & $-4.83 e^{-7.5 s}$ & $2.20(30 s+1) e^{-3.0 s}$ & $-1.49 e^{-80 s}$ \\
\hline & $(23.9 s+1)(4.6 s+1)$ & $(21.5 s+1)(4.3 s+1)$ & $(20.8 s+1)(20.8 s+1)$ & $(20.4 s+1)(4 s+1)$ \\
\hline \multirow{2}{*}{ CV4 } & $1.27(110 s+1) e^{-1.2 s}$ & $3.74 e^{-0.1 s}$ & $0.17(-130 s+1) e^{-0.0 s}$ & $5.34 e^{-0.0 s}$ \\
\hline & $(107 s+1)(9 s+1)$ & $\overline{(8.1 s+1)}$ & $(85 s+1)(3 s+1)$ & $(0.025 s+1)$ \\
\hline
\end{tabular}


Table 3. Scenarios and control structures tested in this work

\begin{tabular}{lll}
\hline Scenario & Control structure & Heat integration \\
\hline 1 & Decentralized (PID) & No \\
2 & Decentralized (PID) & Yes \\
3 & MPC (CL1 CL3) and decentralized (CL2 CL4) & Yes \\
4 & MPC & Yes \\
\hline
\end{tabular}


Table 4. Sensitivity analysis of disturbances on controlled variables when the disturbance is the feed composition

\begin{tabular}{|c|c|c|c|c|}
\hline Unscaled values & $\partial C V_{1} / \partial D V(\mathrm{~K})$ & $\partial C V_{2} / \partial D V(\mathrm{~Pa})$ & $\partial C V_{3} / \partial D V^{(-)}$ & $\partial C V_{4} / \partial D V^{(P a)}$ \\
\hline $\begin{array}{l}\text { Heat integration } \\
\text { (scenarios 2-4) }\end{array}$ & -12.7 & $-32.110^{3}$ & 0.138 & 3251 \\
\hline $\begin{array}{c}\text { No heat integration } \\
\text { (scenario } 1)\end{array}$ & -17.0 & $58.210^{3}$ & $4.3010^{-2}$ & 97.6 \\
\hline Scaled values & $s a_{1}$ & $\mathrm{sa}_{2}$ & $\mathrm{sa}_{3}$ & $\mathrm{Sa}_{4}$ \\
\hline $\begin{array}{l}\text { Heat integration } \\
\text { (scenarios 2-4) }\end{array}$ & -5.79 & -0.802 & 77 & 0.708 \\
\hline $\begin{array}{c}\text { No heat integration } \\
\text { (scenario } 1)\end{array}$ & -7.71 & 1.46 & 0.863 & $2.1010^{-2}$ \\
\hline
\end{tabular}


Table 5. Control metrics for a $+10 \%$ disturbance in feed concentration

\begin{tabular}{l|llll|llll}
\hline \multicolumn{3}{c}{ IAE (min) } & \multicolumn{4}{c}{ TV (dimensionless) } \\
\hline & Loop 1 & Loop 2 & Loop 3 & Loop 4 & Loop 1 & Loop 2 & Loop 3 & Loop 4 \\
\hline Scenario 1 & $3.7010^{-2}$ & 0.100 & $1.1810^{-3}$ & $2.1910^{-5}$ & 1.39 & 1.36 & 2.26 & 1.86 \\
Scenario 2 & $8.6110^{-2}$ & 0.302 & $3.0010^{-3}$ & 3.49 & 1.00 & 1.01 & 1.47 & 2.09 \\
Scenario 3 & $9.6310^{-2}$ & 0.195 & 0.231 & 3.45 & 1.00 & 1.01 & 1.41 & 1.33 \\
Scenario 4 & $1.6010^{-2}$ & 0.386 & 0.223 & 2.90 & 2.17 & 3.05 & 2.00 & 2.80 \\
\hline
\end{tabular}


Table 6. Energy and production metrics for a $+10 \%$ disturbance in feed concentration (1h simulation). Test refers to the average values during $1 \mathrm{~h}$ simulation. Design refers to the steady state values for the process after $+10 \%$ disturbance in feed composition

\begin{tabular}{l|ccc|ccc|ccc}
\hline & \multicolumn{3}{c}{$\begin{array}{c}\text { Production } \\
(\mathrm{kmol} \text { ethanol/h) }\end{array}$} & \multicolumn{3}{c}{$\begin{array}{c}\text { Recovery } \\
(\mathrm{w} / \mathrm{w} \%)\end{array}$} & \multicolumn{3}{c}{$\begin{array}{c}\text { Energy consumption } \\
\text { (MJ/kmol ethanol) }\end{array}$} \\
\hline & Test & Design & Diff (\%) & Test & Design & Diff (\%) & Test & Design & Diff (\%) \\
\hline Scenario 1 & 55.35 & 55.91 & -1.01 & 80.13 & 80.39 & -0.33 & 204.3 & 203.3 & 0.48 \\
Scenario 2 & 49.11 & 49.96 & -1.69 & 78.68 & 81.70 & -3.69 & 142.5 & 140.1 & 1.72 \\
Scenario 3 & 49.51 & 49.96 & -0.89 & 78.80 & 81.70 & -3.54 & 141.4 & 140.1 & 0.90 \\
Scenario 4 & 49.55 & 49.96 & -0.82 & 80.14 & 81.70 & -1.90 & 141.3 & 140.1 & 0.82 \\
\hline
\end{tabular}


Table 7. Control metrics for for simulated plant operation (32 h)

\begin{tabular}{l|llll|llll}
\hline \multicolumn{3}{c}{ IAE (min) } & \multicolumn{4}{c}{ TV (dimensionless) } \\
\hline & Loop 1 & Loop 2 & Loop 3 & Loop 4 & Loop 1 & Loop 2 & Loop 3 & Loop 4 \\
\hline Scenario 1 & 0.187 & 1.32 & 0.158 & $2.2910^{-3}$ & 3.20 & 21.8 & 56.3 & 83.5 \\
Scenario 2 & 0.470 & 2.94 & $9.9110^{-2}$ & 111 & 2.71 & 27.3 & 86.9 & 74.9 \\
Scenario 3 & 0.105 & 1.39 & 1.67 & 98.6 & 4.85 & 2.46 & 4.19 & 22.1 \\
Scenario 4 & 0.215 & 6.66 & 1.84 & 110 & 14.3 & 22.3 & 16.4 & 30.5 \\
\hline
\end{tabular}


Table 8. Energy and production metrics for simulated plant operation (32 h-period). Test refers to the average values during $32 \mathrm{~h}$ simulation. Design refers to the steady state values at the nominal operating point

\begin{tabular}{l|ccc|ccc|ccc}
\hline & \multicolumn{3}{c}{$\begin{array}{c}\text { Production } \\
(k m o l \text { ethanol/h) }\end{array}$} & \multicolumn{3}{c}{$\begin{array}{c}\text { Recovery } \\
(\mathrm{w} / \mathrm{w} \%)\end{array}$} & \multicolumn{3}{c}{$\begin{array}{c}\text { Energy consumption } \\
\text { (MJ/kmol ethanol) }\end{array}$} \\
\hline & Test & Design & Diff (\%) & Test & Design & Diff (\%) & Test & Design & Diff (\%) \\
\hline Scenario 1 & 53.74 & 53.77 & -0.06 & 75.67 & 76.12 & -0.59 & 217.1 & 216.5 & 0.28 \\
Scenario 2 & 47.17 & 47.25 & -0.17 & 77.83 & 78.05 & -0.28 & 148.4 & 148.0 & 0.26 \\
Scenario 3 & 47.19 & 47.25 & -0.13 & 77.86 & 78.05 & -0.26 & 148.4 & 148.0 & 0.26 \\
Scenario 4 & 47.17 & 47.25 & -0.17 & 77.83 & 78.05 & -0.28 & 148.4 & 148.0 & 0.26 \\
\hline
\end{tabular}




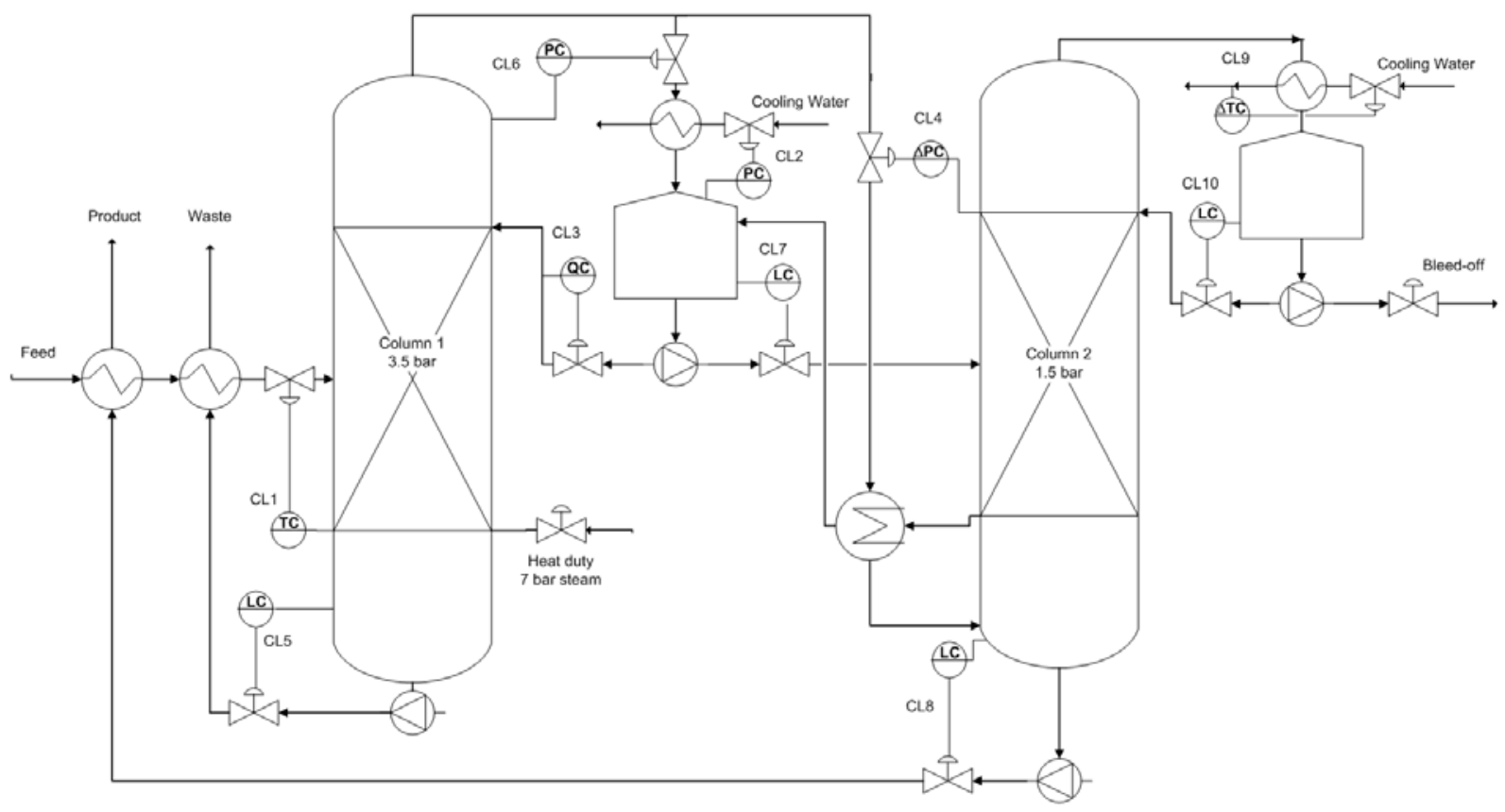

Figure 1. Flowsheet of the plant of ethanol recovery indicating the existing control system 


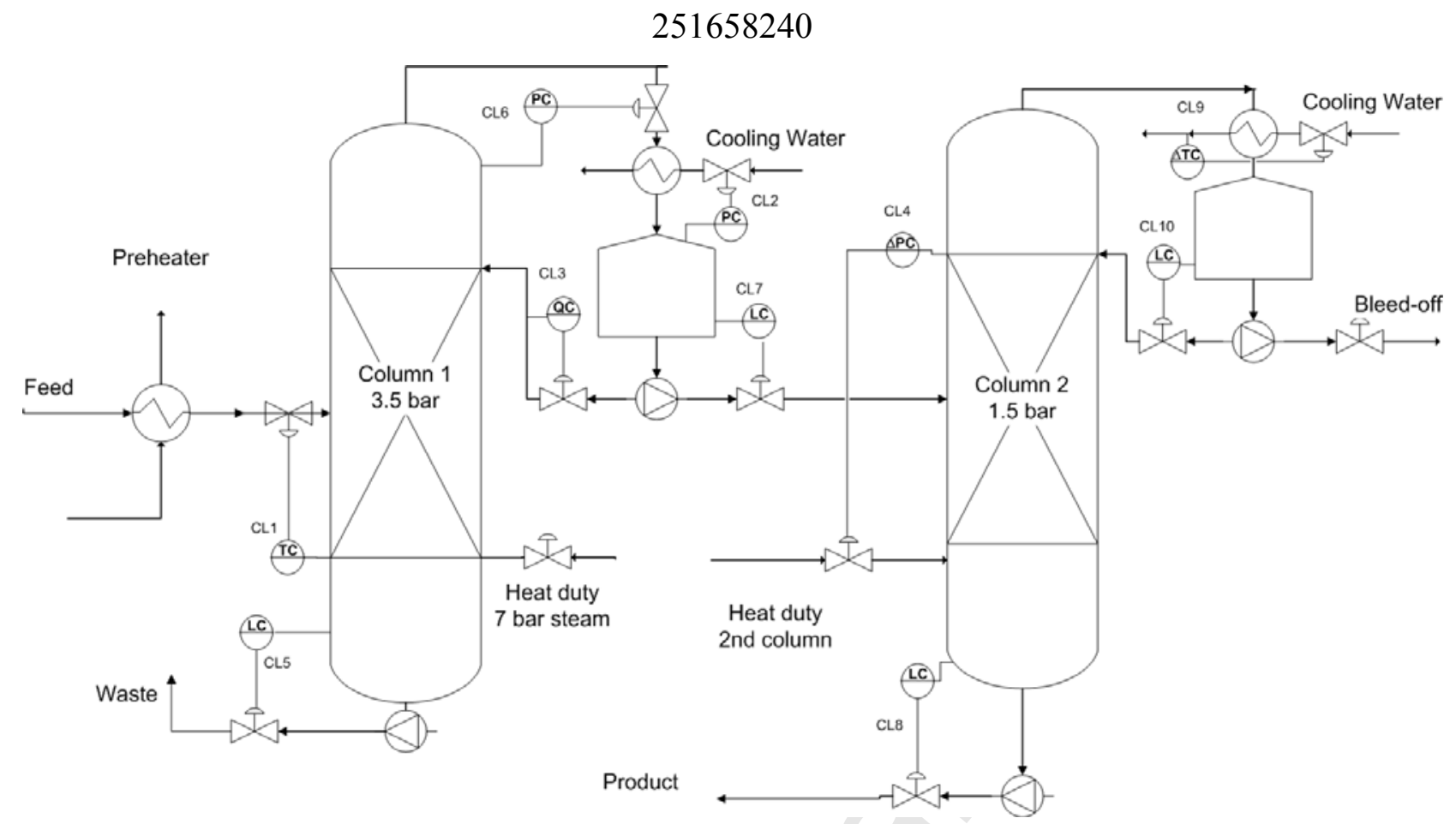

Figure 2. Flowsheet of the alternative plant without heat integration streams 

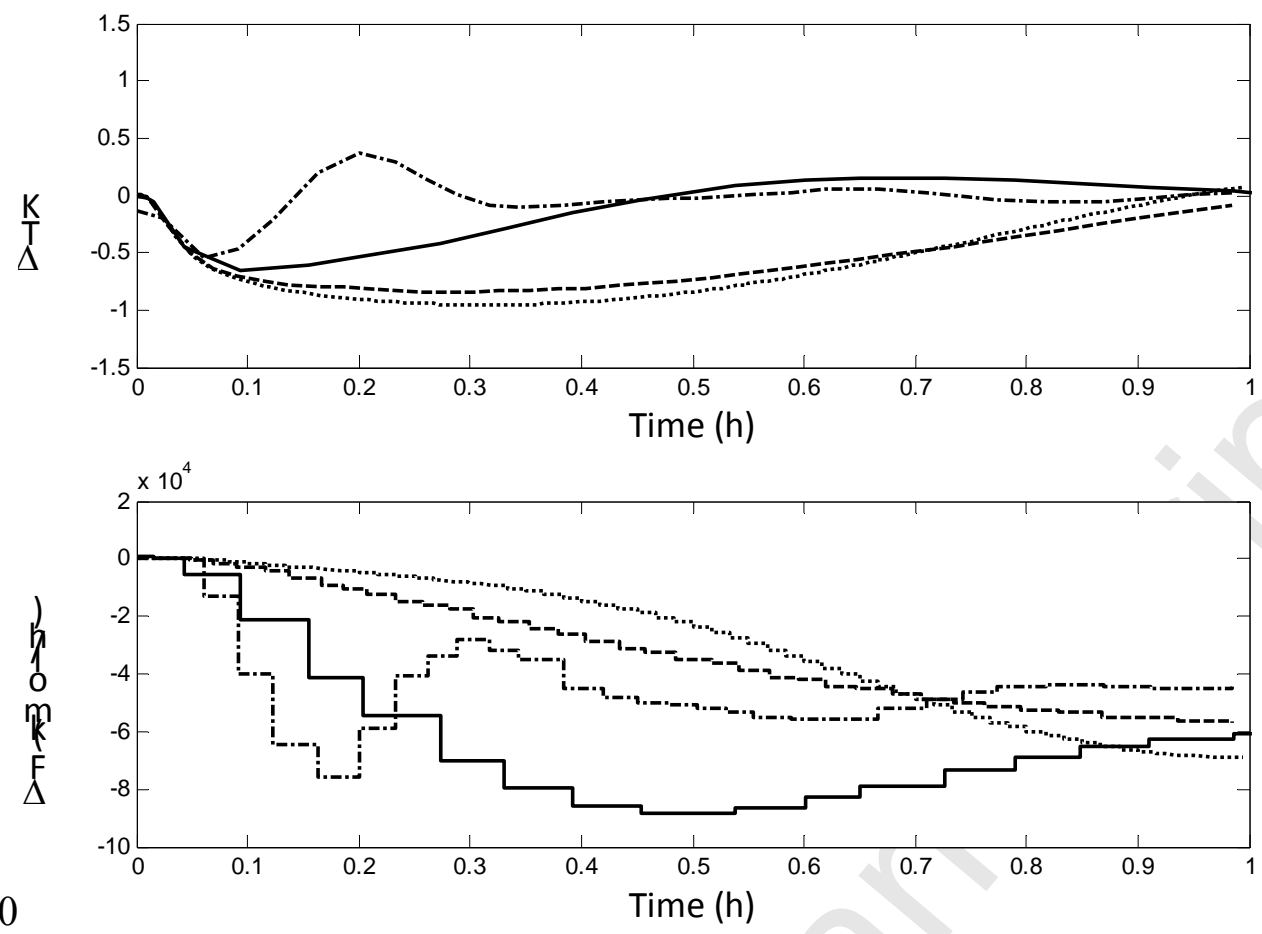

251658240

Figure 3. Controlled (T stripping section, top) and manipulated variable (feed flow, bottom) response of loop 1 for a $+10 \%$ disturbance in feed concentrate. Lines correspond to scenario $1(-)$, scenario $2(--)$, scenario $3(\cdots)$, scenario $4(\cdot-)$. 


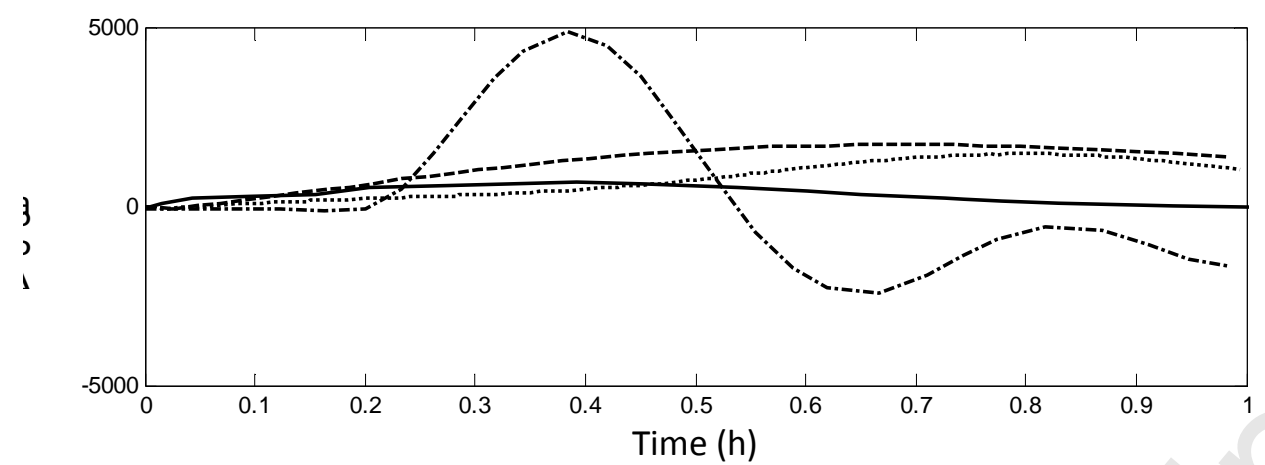

251658240

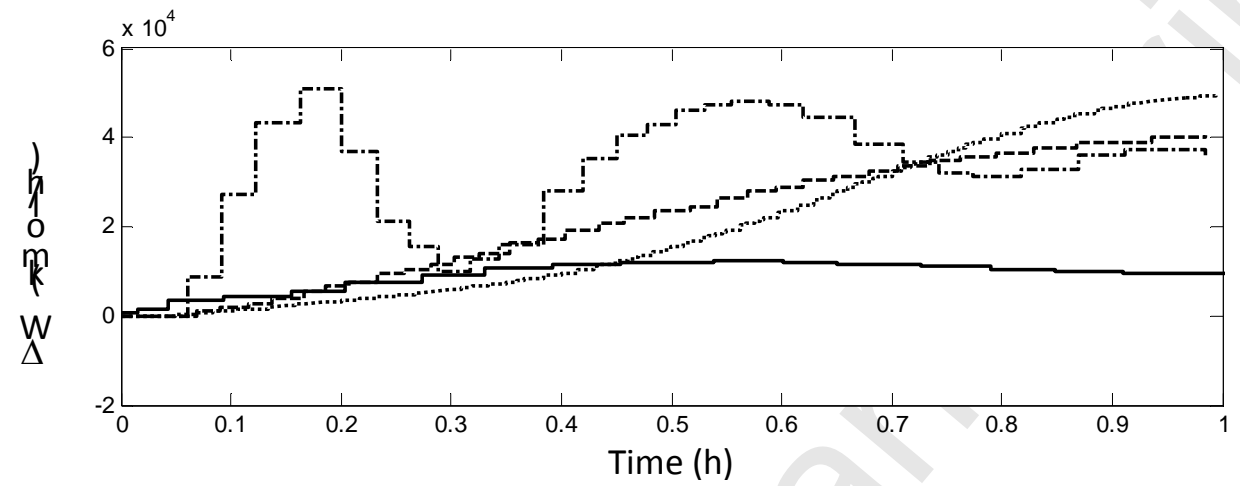

Figures 4. Controlled (pressure in reflux drum, top) and manipulated variable (cooling water flow, bottom) response of loop 2 for a $+10 \%$ disturbance in feed concentrate. Lines correspond to scenario $1(-)$, scenario $2(--)$, scenario $3(\cdots)$, scenario $4(\cdot-)$. 


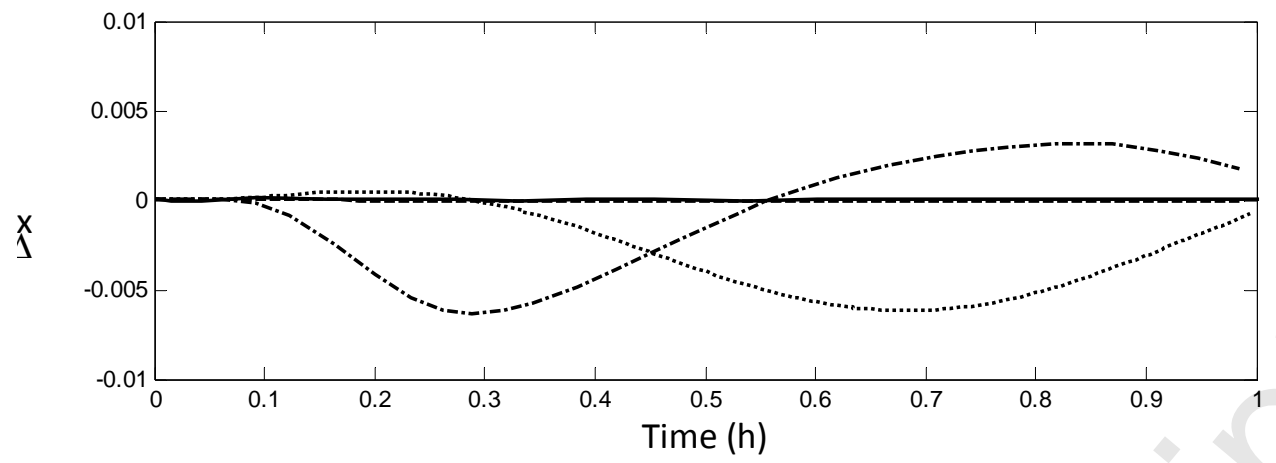

251658240

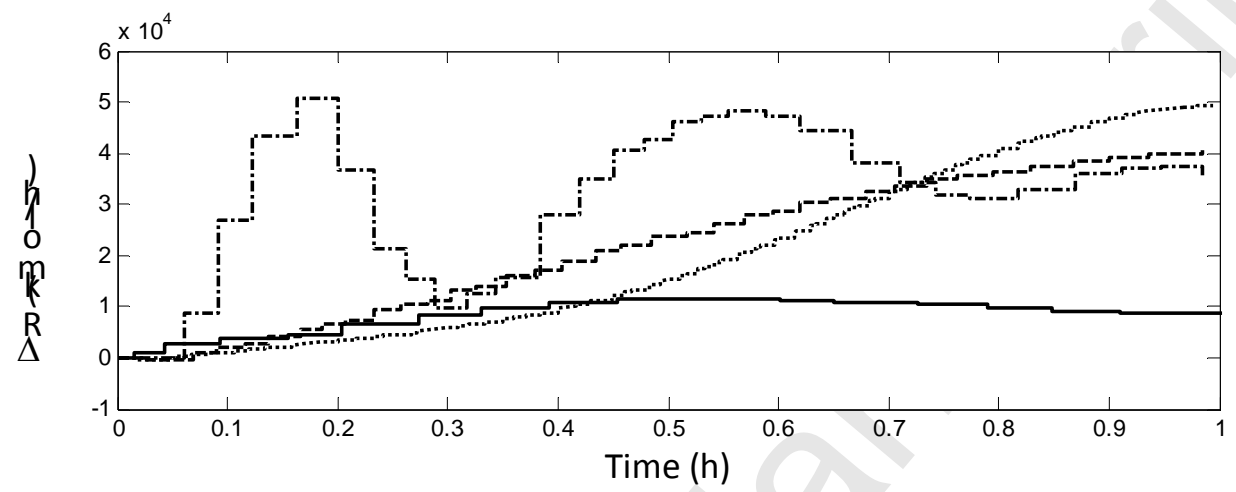

Figures 5. Controlled (composition in reflux drum, top) and manipulated variable (reflux flow, down) response of loop 3 for a $+10 \%$ disturbance in feed concentrate. Lines correspond to scenario $1(-)$, scenario $2(--)$, scenario $3(\cdots)$, scenario $4(\cdot-)$.
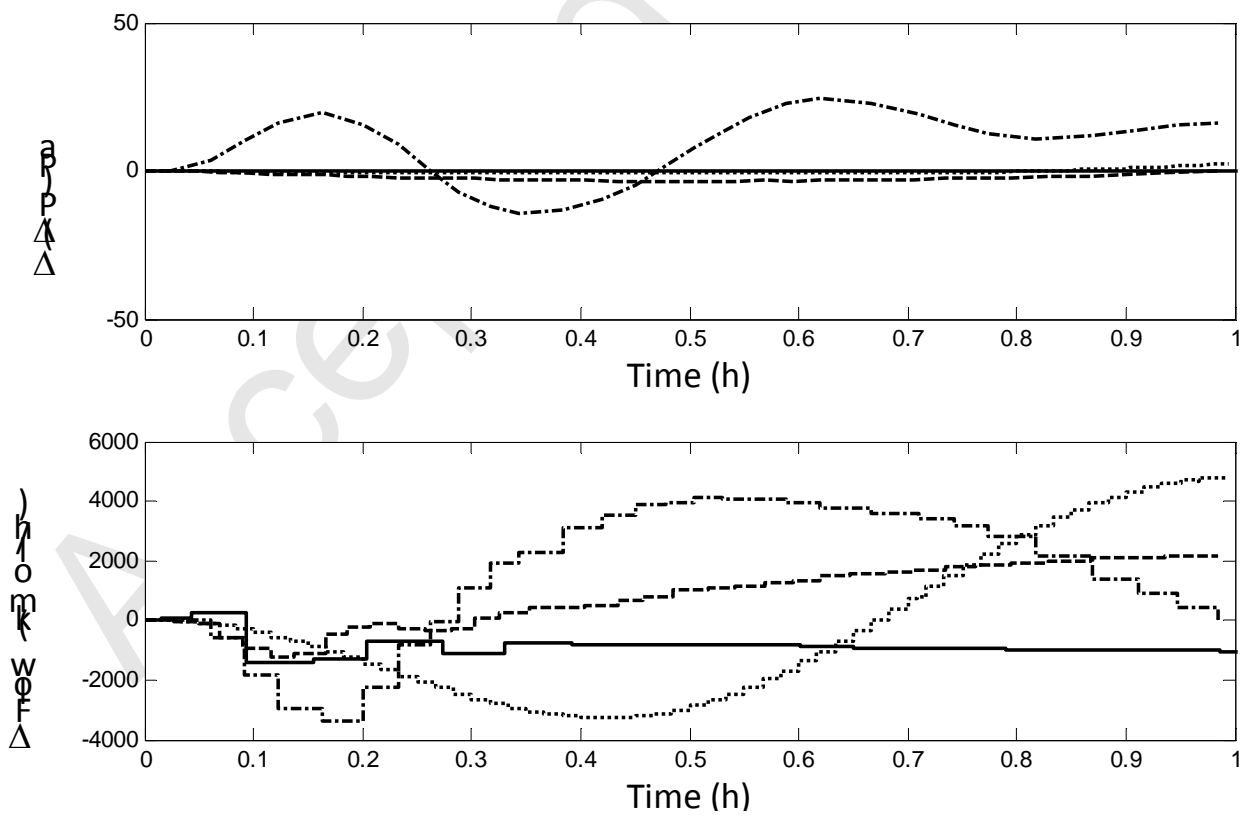

251658240

Figures 6. Controlled (pressure drop in the second column, top) and manipulated variable (vapour flow to the second column reboiler, bottom) response of loop 4 for a $+10 \%$ disturbance in feed concentrate. Lines correspond to scenario $1(-)$, scenario $2(--)$, scenario $3(\cdots)$, scenario $4(\cdot-)$. 

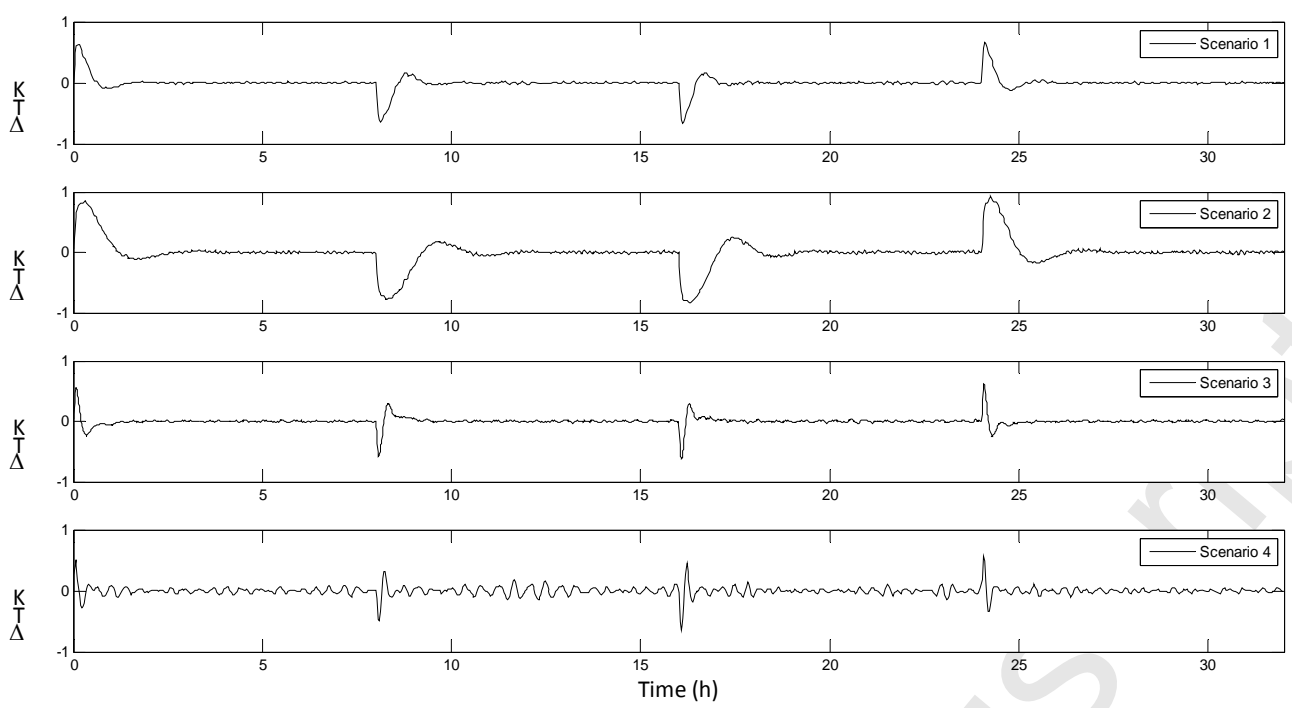

251658240

Figure 7.

Controlled variable in loop 1 (temperature at stripping section) during the simulation of the plant operation
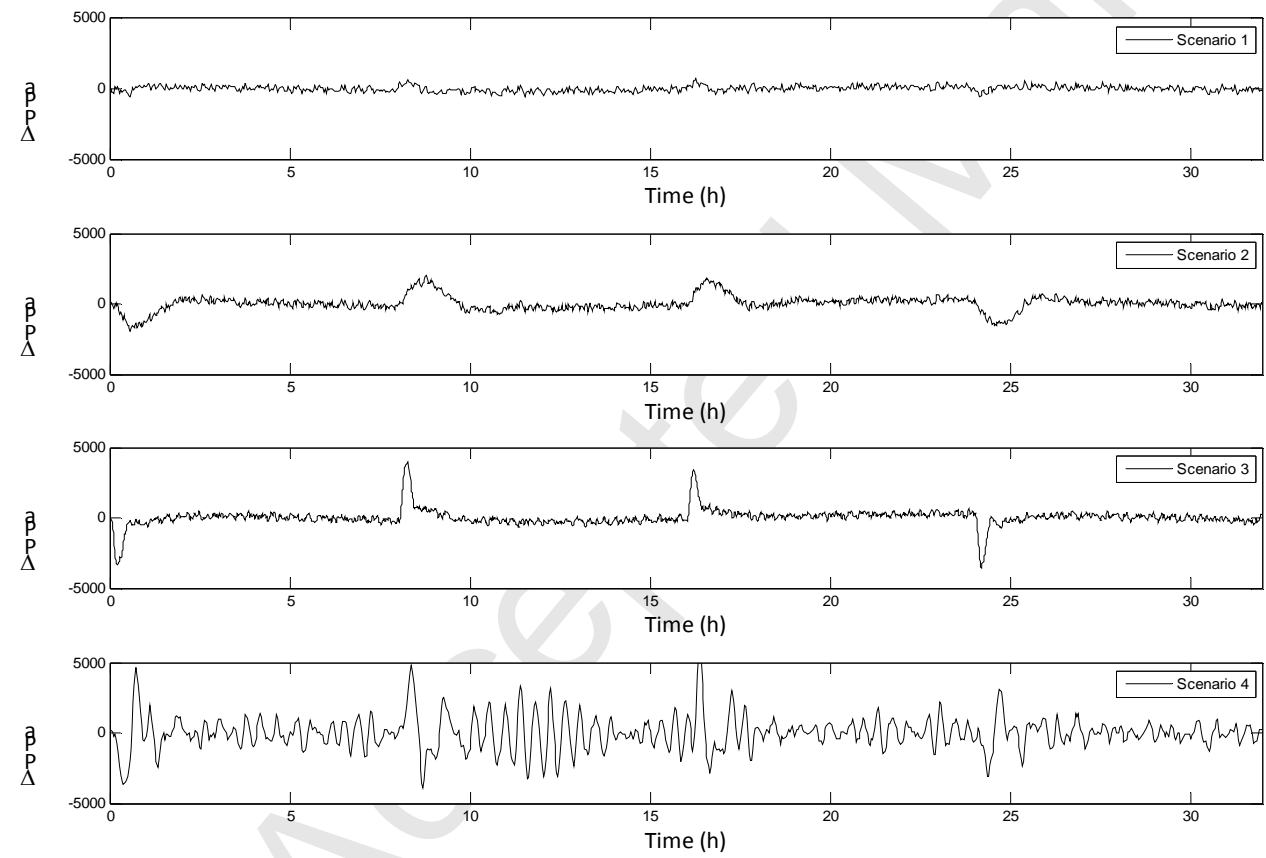

Figure 8. Controlled variable in loop 2 (pressure in the reflux drum) during the simulation of the plant operation 

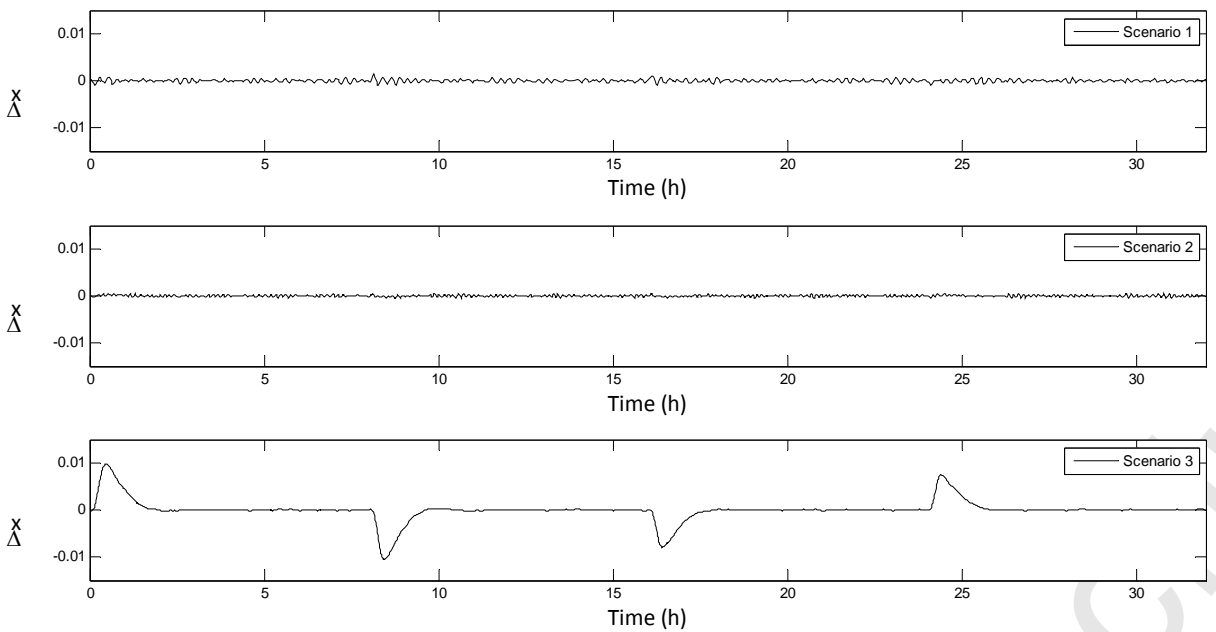

251658240

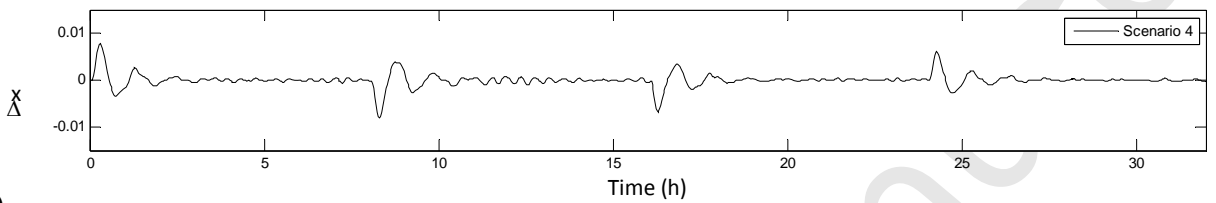

Figure 9. Controlled variable in loop 3 (composition of reflux drum) during the simulation of the plant operation
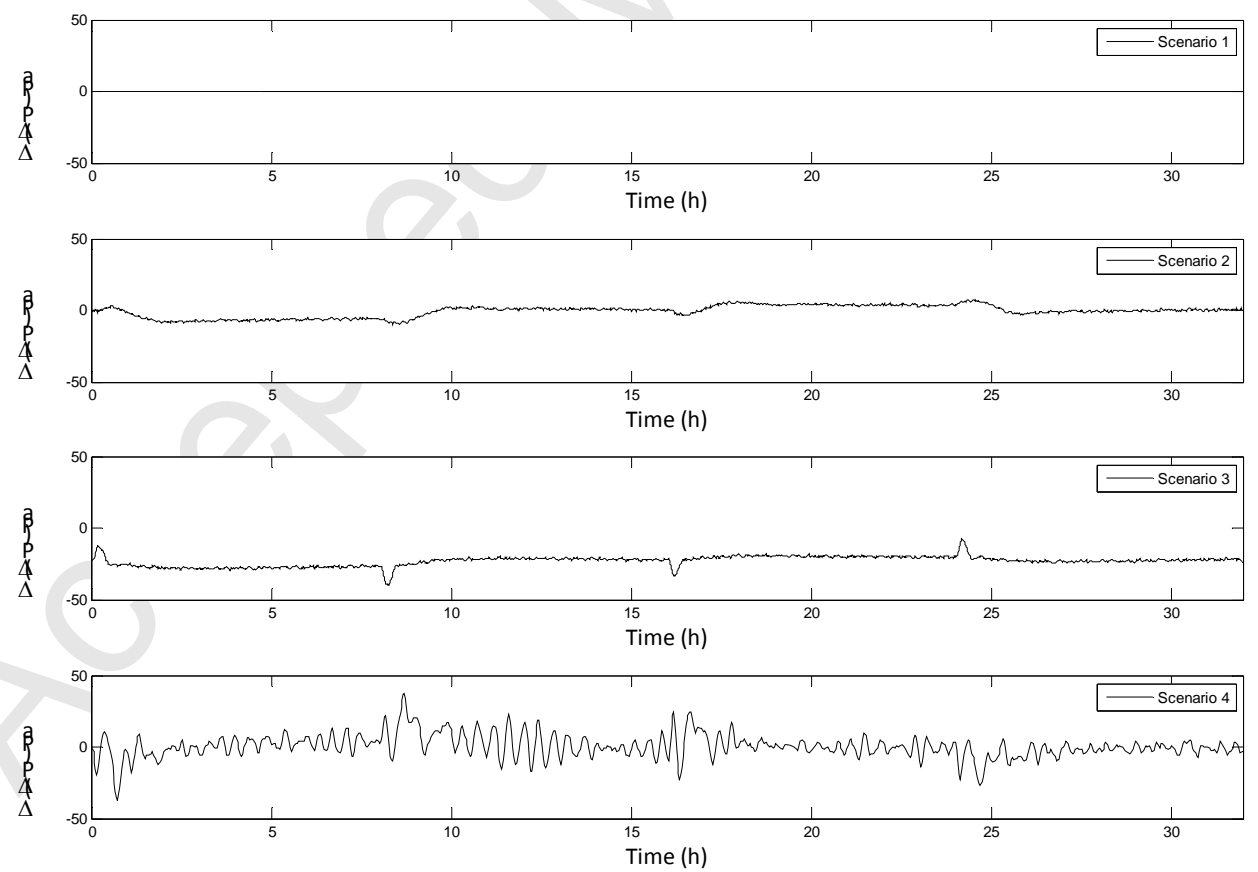

251658240

Figure 10. Controlled variable in loop 4 (pressure drop in second column) during the simulation of the plant operation 